\title{
Erratum to: Analysis of publications on sturgeon research between 1996 and 2010
}

\section{Jarić · J. Gessner}

Published online: 31 March 2012

(C) Akadémiai Kiadó, Budapest, Hungary 2012

\section{Erratum to: Scientometrics (2012) 90:715-735 DOI 10.1007/s11192-011-0583-7}

In the original publication of this article, affiliation of the first author is incomplete. The complete affiliation of the first author is given in this erratum.

The online version of the original article can be found under doi:10.1007/s11192-011-0583-7.

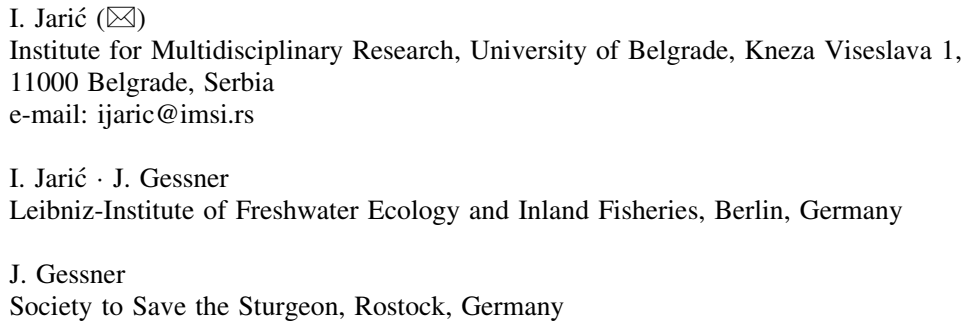

